INTESTINE INFLAMMATION

\title{
Leptin receptor expression on T lymphocytes modulates chronic intestinal inflammation in mice
}

\author{
B Siegmund, J A Sennello, J Jones-Carson, F Gamboni-Robertson, H A Lehr, A Batra, I Fedke, \\ M Zeitz, G Fantuzzi
}

Gut 2004;53:965-972. doi: 10.1136/gut.2003.027136

See end of article for authors' affiliations

.....................

Correspondence to: Dr G Fantuzzi, University of Colorado, Department of Medicine, Box B168,

4200 East Ninth Ave.,

Denver, CO 80262, ÚSA; Giamila.Fantuzzi@

uchsc.edu

Accepted for publication 10 December 2003
Background: Leptin regulates appetite through the long isoform of its receptor in the hypothalamus. Although leptin regulates immune responses, it is still unknown whether a direct effect of leptin on lymphocytes is required.

Aims: To clarify whether expression of leptin receptors on T lymphocytes modulates intestinal inflammation in mice.

Methods: The model of colitis induced by transfer of $C D 4^{+} C D 45 R B^{\text {high }}$ (RB ${ }^{\text {high) }}$ ) cells into scid mice was used. Wild-type (WT) or leptin receptor deficient $(d b / d b) ~ R B^{\text {high }}$ cells were transferred into scid mice and development of colitis evaluated.

Results: Leptin receptors were expressed on both $\mathrm{RB}^{\text {high }}$ and $\mathrm{RB}{ }^{\text {low }}$ cells. Intestinal lymphocytes of mice with colitis expressed high leptin levels compared with healthy controls whereas the opposite was true for serum leptin levels. Transfer of RB ${ }^{\text {high }}$ cells from $\mathrm{db} / \mathrm{db}$ mice induced delayed disease compared with transfer of WT cells. A high rate of apoptosis in lamina propria lymphocytes and reduced cytokine production were observed early on in scid mice receiving $\mathrm{db} / \mathrm{db}$ RB high cells. These effects were not due to the high levels of glucocorticoids present in $\mathrm{db} / \mathrm{db}$ mice as administration of corticosterone to WT mice failed to reproduce this phenomenon. High expression of peroxisome proliferator activated receptor $\gamma$ was observed in the colon of recipients of $d b / d b$ compared with WT cells. Freshly isolated $d b / d b$ RB high cells produced low levels of interferon $\gamma$. Despite delayed onset of colitis, as disease progressed differences between mice receiving $W T$ or $d b / d b$ cells were no longer apparent.

Conclusions: These results suggest that leptin affects the immune response, partly by acting on the long isoform of its receptor expressed on T lymphocytes. eptin is best known for its ability to regulate food intake and metabolism. ${ }^{1}$ At the same time, leptin also regulates -immune responses. ${ }^{2}$ Most immune cell types express functional leptin receptors and leptin skews the immune response towards a Thl phenotype. ${ }^{2}$ Although adipocytes are quantitatively the most important source of leptin, a variety of cells-including immune cells-express this protein. ${ }^{3}$

Mice deficient for production of leptin ( $o b / o b$ mice) or the long isoform of its receptor (LEPR-B) $(d b / d b$ mice) are resistant in a variety of experimental models of inflammation/autoimmunity. ${ }^{4-6}$ In particular, $o b / o b$ mice are resistant to intestinal inflammation induced by administration of dextran sulphate sodium or trinitrobenzene sulphonic acid. ${ }^{7}$ In these models, resistance to colitis in the absence of leptin is associated with reduced cytokine production and increased apoptosis of lamina propria lymphocytes. Resistance to Clostridium difficile toxin A induced enteritis has also been demonstrated in $o b / o b$ mice. ${ }^{8}$

LEPR-B, the signalling isoform of the leptin receptor, is expressed both centrally and peripherally in a variety of cell types. $^{2}$ While the appetite regulating effects of leptin are mediated through expression of LEPR-B in the hypothalamus, ${ }^{9}$ it is currently unknown whether the immune regulating activities of leptin require central and/or peripheral expression of leptin receptors. In vitro, the biological effects of leptin on immune cells have been demonstrated, suggesting a possible direct effect. ${ }^{10-12}$

An additional confounding factor in most of the studies that demonstrated an effect of leptin on immune responses is the systemic alteration in the metabolic and hormonal homeostasis of $o b / o b$ and $d b / d b$ mice, the models usually employed to study leptin activities. Among other abnormalities, these mice are massively obese, insulin resistant, and have high levels of glucocorticoids. ${ }^{1}$ As each of these factors could influence immune responses, it has been difficult to date to dissect the direct contribution of leptin from the participation of the other players.

To approach this issue, the model of colitis induced by transfer of $\mathrm{CD}^{+} \mathrm{CD} 45 \mathrm{RB}^{\text {high }}$ cells $\left(\mathrm{RB}^{\text {high }}\right)$ into scid mice was employed. ${ }^{13}$ When $\mathrm{RB}^{\text {high }}$ cells are injected into $\mathrm{T}$ cell deficient mice, they proliferate, home to the gut, and induce intestinal inflammation. T helper 1 (Thl) cytokines, such as interferon $\gamma($ IFN- $\gamma)$, are major players in the induction of this disease, whereas interleukin (IL)-10 and transforming growth factor $\beta$ (TGF- $\beta$ ) play a protective role. ${ }^{13}{ }^{14}$

To evaluate the role of leptin, we compared the disease inducing ability of wild-type (WT) and $d b / d b \mathrm{RB}^{\text {high }}$ cells injected into LEPR-B competent scid mice. The use of this model has two advantages: (1) the recipient mouse expresses LEPR-B on each cell type. The only LEPR-B deficient cells present in the system are the donor derived RB ${ }^{\text {high }}$ cells; (2) injected $d b / d b R^{\text {high }}$ cells have the opportunity to exert their function in a "normal" environment-that is, in a mouse that is not obese or diabetic and has normal levels of

Abbreviations: $d b / d b$, leptin receptor deficient mice; WT, wild-type mice; PPAR $\gamma$, peroxisome proliferator activated receptor $\gamma$; LEPR, leptin receptor; IFN- $\gamma$, interferon $\gamma$; IL, interleukin; TGF- $\beta$, transforming growth factor $\beta$; Th1, T helper 1; IEL, intraepithelial lymphocytes; LPL, lamina propria lymphocytes; MLN, mesenteric lymph node cells; MIP-2, macrophage inflammatory protein 2; TNF- $\alpha$, tumour necrosis factor $\alpha$; GC, glucocorticoids; CS, corticosterone 
glucocorticoids. Therefore, the possible contribution of these factors is eliminated.

\section{METHODS}

Mice

Animal protocols were approved by the animal studies committee of the University of Colorado Health Sciences Center. Six to eight week old male C57BL/KS $d b / d b$ mice $\left(\mathrm{C} 57 \mathrm{BLKS} / \mathrm{J}-m+/+\mathrm{Lepr}^{d b}\right)\left(\mathrm{H} 2^{\mathrm{d}}\right)$ and their non-obese $(+/+$ and $d b /+)$ littermates, as well as Balb/c mice, were obtained from the Jackson Laboratories (Bar Harbor, Maine, USA). Six to eight week old male Balb/c scid mice (CB-17 SCID) ( $\mathrm{H}^{\mathrm{d}}$ ) were from Charles River (Wilmington, Massachusetts, USA). Experiments were replicated using $d b / d b$ mice and their nonobese littermates in a C57BL/6 background (Jackson Laboratories) $\left(\mathrm{H}_{2}{ }^{\mathrm{b}}\right)$. In this case, $\mathrm{C} 57 \mathrm{BL} / 6$ scid mice were used as recipients (Jackson Laboratories). For experiments evaluating the role of glucocorticoids in the development of colitis, WT C57BLKS/J received drinking water supplemented with corticosterone phosphate (Sigma Chemicals, St Louis, Missouri, USA) at $2 \mathrm{mg} / \mathrm{ml}$ for one month prior to isolation of splenocytes. Serum corticosterone levels were measured using an ELISA kit from Assay Designs, Inc. (Ann Arbor, Michigan, USA).

\section{Cell sorting, administration, and culture}

A splenocyte suspension from WT and $d b / d b$ mice was prepared. $\mathrm{CD}^{+}$cells were positively enriched using L3T4 magnetic microbeads (Miltenyi Biotec, Auburn, California, USA). Cells were labelled with anti-CD4 and anti-CD45RB antibodies (Caltag, Burlingame, California, USA) and sorted into $\mathrm{RB}^{\text {high }}$ and $\mathrm{RB}^{\text {low }}$ cells. Sorted $\mathrm{RB}^{\text {high }}$ cells $\left(4 \times 10^{5} /\right.$ mouse $)$ were injected intraperitoneally into scid recipients. Alternatively, sorted $\mathrm{RB}^{\text {high }}$ and $\mathrm{RB}^{\text {low }}$ cells were cultured for 24 or 48 hours at $2.5 \times 10^{6} / \mathrm{ml}$ in 96 well plates in the presence of plate bound anti-CD $3 \epsilon$ antibodies (BD Pharmingen, San Diego, California, USA) at $1 \mu \mathrm{g} / \mathrm{ml}$, with or without soluble anti-CD28 (BD Pharmingen; $1 \mu \mathrm{g} / \mathrm{ml}$ ) or murine recombinant leptin (R\&D Systems, Minneapolis, Minnesota, USA; $1 \mu \mathrm{g} / \mathrm{ml}$ ).

\section{Clinical and histological assessment of colitis}

Mice were weighed weekly and monitored for the appearance of diarrhoea and blood in the stools. A disease scoring system was applied, as previously described. ${ }^{15}$ Weights were ranked by assigning points as follows: $0=0-5 \%$ weight loss; $1=6-10 \%$ weight loss; $2=11-15 \%$ weight loss; $3=16-20 \%$ weight loss; and $4=>20 \%$ weight loss. Appearance of diarrhoea was scored as follows: $0=$ well formed pellets; 2 = pasty and semiformed stools that did not adhere to the anus; and $4=$ liquid stools that did adhere to the anus. Appearance of blood in the stools was scored as follows: $0=$ no blood using hemoccult (Beckman Coulter, Palo Alto, California, USA); $2=$ positive hemoccult; and $4=$ gross bleeding. Total scores given for wasting, diarrhoea, and stool blood were added and divided by 3 for a maximal disease score of 4 . Post mortem, the entire colon was excised and a $1 \mathrm{~cm}$ segment of the transverse colon was fixed in $10 \%$ buffered formalin for histological analysis. Paraffin sections were stained with haematoxylin/eosin. Four to six colon rings were obtained from each $1 \mathrm{~cm}$ colon segment and were thus available for histological examination. Histological scoring was performed in a blinded fashion by a pathologist (HAL) as a combined score of inflammatory cell infiltration (0-3) and tissue damage (0-3), as described previously. ${ }^{16}$

\section{Colon culture}

A segment of the colon was removed, cut open longitudinally, and washed in phosphate buffered saline containing penicillin and streptomycin. The colon was then further cut into strips of approximately $1 \mathrm{~cm}^{2}$ and placed in 24 flat bottom well culture plates containing $1 \mathrm{ml}$ of RPMI supplemented with penicillin and streptomycin. Strips were incubated at $37^{\circ} \mathrm{C}$ for 24 hours. Culture supernatants were then harvested and assayed for cytokines.

\section{Preparation of intraepithelial (IEL), lamina propria (LPL), and mesenteric lymph node (MLN) cells}

IEL and LPL were isolated from the colon as described previously. ${ }^{7}$ Single cell suspensions of MLN were prepared by passing cells through a $100 \mu \mathrm{M}$ strainer. LPL and MLN were cultured for 24 hours at $2.5 \times 10^{6} / \mathrm{ml}$ in 96 well plates in the presence of plate bound anti-CD $3 \epsilon$ antibodies (BD Pharmingen) at $1 \mu \mathrm{g} / \mathrm{ml}$.

\section{Cytokine and leptin measurements}

Murine IL-18, IL-10, macrophage inflammatory protein 2 (MIP-2), IL-10, and tumour necrosis factor $\alpha$ (TNF- $\alpha$ ) levels were measured using an electrochemiluminescence method, as described previously. ${ }^{17}$ IFN- $\gamma$, IL-4, IL-6, and leptin were measured using specific ELISA (BD Pharmingen and R\&D Systems). TGF- $\beta$ levels were measured after activation with $\mathrm{HCl}$ and subsequent neutralisation with an ELISA using antihuman TGF- $\beta 1$ antibodies from BD Pharmingen.

\section{Flow cytometry}

Flow cytometry followed routine procedures using $1 \times 10^{5}$ cells per sample. Staining with annexin $\mathrm{V}$ and propidium iodide (BD Pharmingen) was used for evaluation of the rate of apoptosis in LPL. Surface marker expression was evaluated using antibodies from BD Pharmingen and Caltag. Analysis was conducted on a FACSCalibur (BD Pharmingen) using the Cell Quest analysis program (BD Pharmingen). Markers evaluated included CD3, CD4, CD $8 \alpha$ and $\beta, C D 25, C D 69, \alpha_{4} \beta_{5}$, and $\alpha_{4} \beta_{\text {int }}$.

\section{Immunohistochemistry}

Frozen sections of transverse colon were analysed for expression of PPAR $\gamma$ using an antibody from Santa Cruz Biotechnology (California, USA) and a staining kit from R\&D Systems.

\section{Confocal microscopy}

LPL and MLN were isolated from control mice and from scid mice that had received WT RB high cells eight weeks earlier. Cells were smeared on slides and fixed with $4 \%$ paraformaldehyde, air dried, and blocked with 10\% normal goat serum. Cells were then incubated overnight with an antileptin

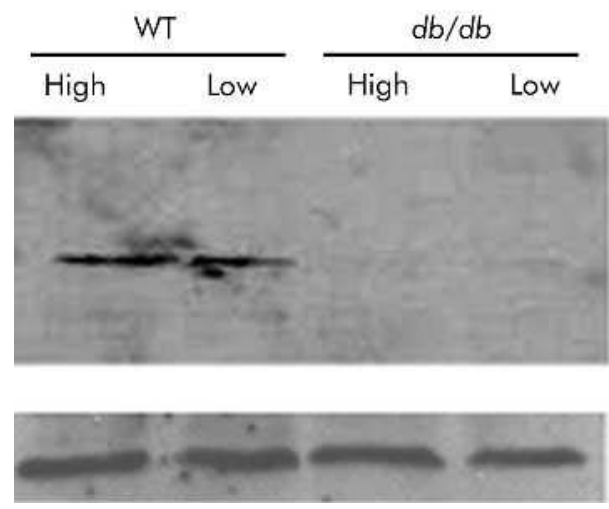

Figure 1 Expression of leptin receptor (LEPR-B) on $R B^{\text {high }}$ and $R B^{\text {low }}$ cells. Western blot analysis for LEPR-B was performed on sorted wildtype (WT) and leptin receptor deficient $(d b / d b) R B^{\text {high }}$ and $R B^{\text {low }}$ cells (top panel). The bottom panel indicates equal protein loading, as evaluated by blotting with an antiactin antibody. 
Table 1 Effect of leptin on cytokine production in $\mathrm{RB}^{\text {high }}$ and RB ${ }^{\text {low }}$ cells

\begin{tabular}{lcl}
\hline & IL-6 $(\mathbf{p g} / \mathbf{m l})$ & IL-10 $(\mathbf{p g} / \mathbf{m l})$ \\
\hline RB high_no leptin & $148.1(22.7)$ & $249.5(22.2)$ \\
RB $^{\text {high_with leptin }}$ & $78.5(32.1)^{*}$ & $<10^{* *}$ \\
RB $^{\text {low }}$-no leptin & $42.4(34.6)$ & $427.7(15.7)$ \\
RB $^{\text {low }}$-with leptin & $29.9(24.4)$ & $354.4(52.2)$ \\
\hline
\end{tabular}

$R B^{\text {high }}$ and $R B^{\text {low }}$ cells were prepared as described in materials and methods and stimulated overnight with anti-CD3 and anti-CD28, in the presence or absence of leptin. Cytokine levels (interleukin (IL)-6 and IL-10) were below detection limits in cells cultured in the absence of anti-CD3 and anti-CD28, with or without leptin.

Data are mean (SEM); $n=3 .{ }^{*} \mathrm{p}<0.05,{ }^{* *} \mathrm{p}<0.01$ versus respective no leptin.

antibody (R\&D Systems) or non-immune rabbit IgG as a negative control. After an overnight incubation, slides were washed and incubated with a secondary antibody conjugated to phycoerythrin. Nuclei were stained blue with bisbenzimide whereas sialoproteins were stained green using Alexa488 conjugated germagglutinin (Molecular Probes, Eugene, Oregon, USA). Slides were washed, mounted, examined using a Leica DM RXA confocal laser scanning system, and analysed with SlideBook Software.

\section{Western blot}

For evaluation of LEPR-B expression on $\mathrm{RB}^{\text {high }}$ and $\mathrm{RB}^{\text {low }}$ cells, sorted cells were resuspended in RIPA buffer and western blot analysis was performed as described previously ${ }^{18}$ using an antimurine LEP-R antibody (R\&D Systems). For evaluation of T-bet levels, the same procedure was employed using an anti-T-bet antibody (Santa Cruz Biotechnology). A goat antiactin antibody (Santa Cruz) was used to control for protein loading.

\section{Statistical analysis}

Data are expressed as mean (SEM). Statistical significance of differences between treatment and control groups were determined by factorial ANOVA and a Bonferroni-Dunn procedure as a post hoc test. Statistical analyses were performed using Stat-View 4.51 software (Abacus Concepts, Calabasas, California, USA).

\section{RESULTS}

Expression of LEPR-B and effects of leptin on RB ${ }^{\text {high }}$ and RB ${ }^{\text {low }}$ cells

Unstimulated freshly sorted (>95\% pure) $\mathrm{RB}^{\text {high }}$ and $\mathrm{RB}^{\text {low }}$ cells obtained from $+/+(\mathrm{WT})$ and $d b / d b$ mice were analysed by western blot for the presence of LEPR-B. Results indicated that in WT cells, LEPR-B was expressed to a comparable extent on both $\mathrm{RB}^{\text {high }}$ and $\mathrm{RB}^{\text {low }}$ cells. On the other hand, as expected, LEPR-B was not expressed in $d b / d b$ cells (fig 1 ). These results were confirmed by reverse transcriptionpolymerase chain reaction analysis of total RNA (not shown). Leptin was able to modulate cytokine production in $\mathrm{RB}^{\text {high }}$ but not in $\mathrm{RB}^{\text {low }}$ cells stimulated in vitro with anti-CD3/CD28. Although the in vitro effects of leptin on IFN- $\gamma$ levels were inconsistent, a significant reduction of IL-6 and IL-10 production was observed in $\mathrm{RB}^{\text {high }}$ but not in $\mathrm{RB}^{\text {low }}$ cells cultured in the presence of leptin (table 1).

Expression of leptin in LPL and MLN of mice with colitis To verify that leptin is expressed locally in intestinal inflammation, LPL and MLN were extracted from controls and from scid mice transferred eight weeks earlier with WT $\mathrm{RB}^{\text {high }}$ cells. As shown in fig 2, cells extracted from diseased mice expressed high levels of leptin compared with cells obtained from healthy controls. However, at the same time,

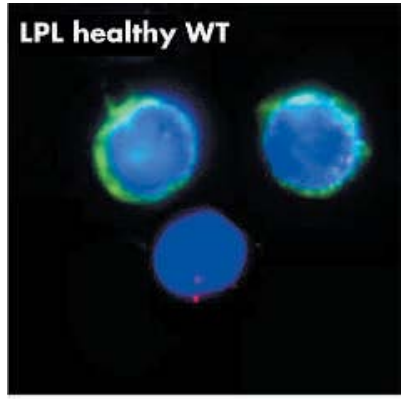

Figure 2 Expression of leptin in lamina propria lymphocytes (LPL) and mesenteric lymph node cells (MLN). LPL and MLN were extracted from healthy controls and from diseased scid mice that had received wild-type (WT) $\mathrm{RB}^{\text {high }}$ cells eight weeks earlier. Cells were stained for leptin (red) and analysed by confocal microscopy. Green represents membrane sialoproteins and blue the nucleus.
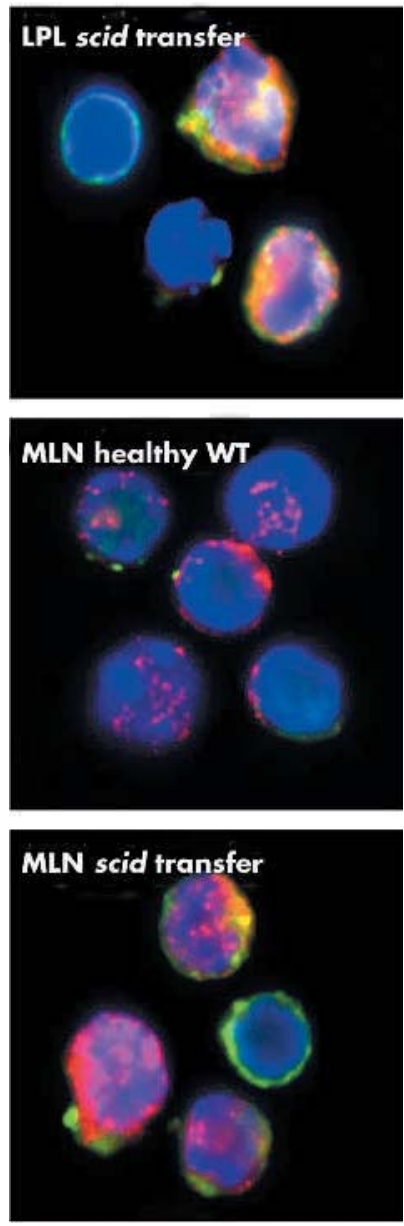

systemic leptin levels were significantly decreased in mice with colitis compared with healthy controls (3.46 (0.76) $v$ $1.76(0.53)$ in control $v$ scid transfer mice, respectively; $\mathrm{n}=5$, $\mathrm{p}<0.05$ ), probably due to the reduction in body weight that accompanies development of disease in this model.

\section{$d b / d b R^{h i g h}$ cells induce delayed colitis compared with WT cells}

Enrichment and sorting of $\mathrm{CD} 4^{+}$cells from the spleen of $+/+$, $d b /+$, and $d b / d b$ mice generated equivalent percentages of $\mathrm{RB}^{\text {high }}$ and $\mathrm{RB}^{\text {low }}$ cells from the different mouse strains, although the absolute number was reduced in $d b / d b$ mice, presumably due to their lymphoid atrophy. ${ }^{2}$ Cell viability did not differ between $+/+, d b /+$, and $d b / d b \mathrm{RB}^{\text {high }}$ cells. No significant differences were observed between mice injected with $+/+$ or $d b /+$ LEPR-B RB ${ }^{\text {high }}$ cells. Therefore, data obtained from mice injected with cells obtained from $+/+$ or $d b /+$ mice were pooled and are presented together in each of the following figures as the WT group. 


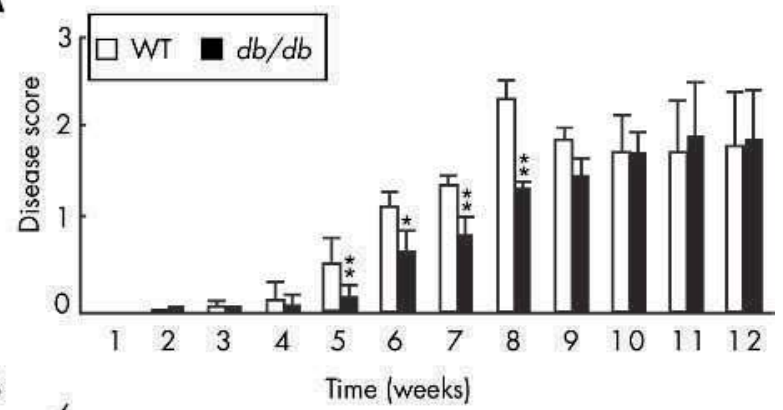

$\mathbf{B}$

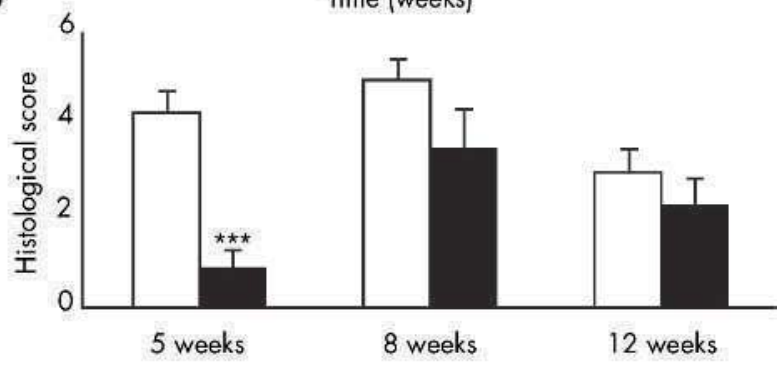

C
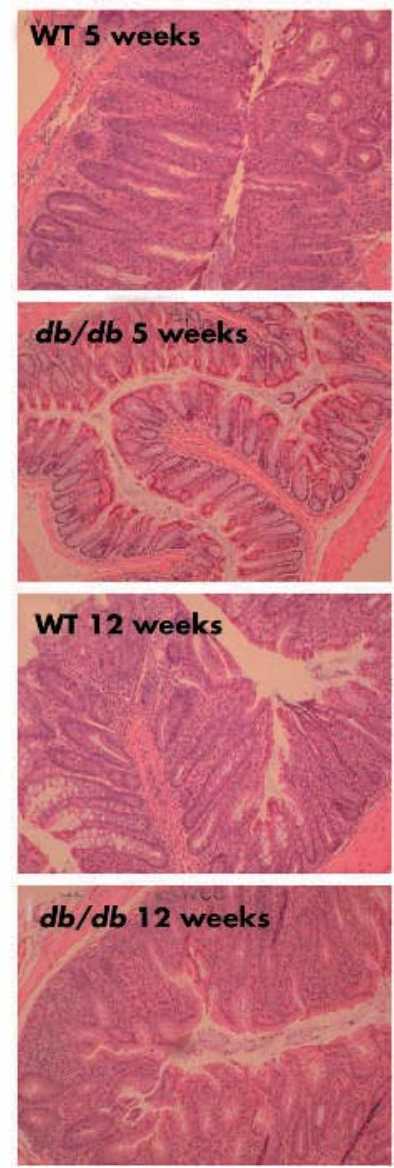

Figure 3 Delayed disease in scid mice injected with leptin receptor deficient $(d b / d b) R B^{h i g h}$ cells. Scid mice were injected with wild-type (WT) or $\mathrm{db} / \mathrm{db}$ RB high cells. (A) Disease score. (B) Histological scores at weeks 5, 8, and 12. (C) Histology at week 5 and week 12.

Representative sections are shown from recipients of WT and $d b / d b$ cells. Data are mean (SEM) of 20 mice per group. ${ }^{*} p<0.05,{ }^{* *} p<0.01$, ${ }^{* * *} \mathrm{p}<0.001$ versus WT.

Evaluation of disease activity scores indicated significantly milder early disease in scid mice injected with $d b / d b$ $\mathrm{RB}^{\text {high }}$ cells compared with mice receiving WT cells (fig 3A).

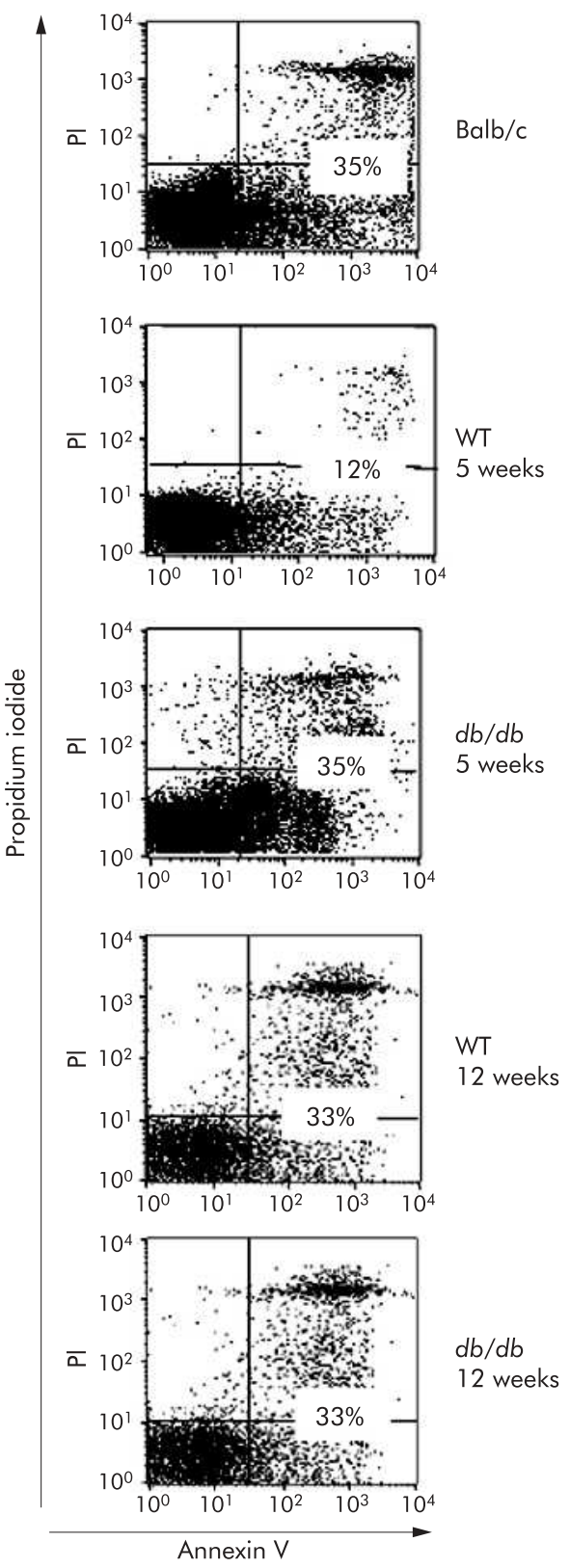

Figure 4 High rates of apoptosis in lamina propria lymphocytes (LPL) of mice receiving leptin receptor deficient $(d b / d b)$ RB high cells. Scid mice were injected with wild-type (WT) or $d b / d b R B^{\text {high }}$ cells. Controls were untreated Balb/c mice. At weeks 5 and 12, a group of three mice per experimental group was sacrificed for valuation of LPL apoptosis by flow cytometry. Results shown are representative of two independent experiments, each with three mice per group.

Differences between the two groups were significant up to week 8 post-injection and disappeared thereafter.

Histological examination of the colon at five weeks revealed marked inflammation in mice injected with WT cells whereas we observed almost no inflammation in mice receiving $d b / d b$ cells (fig $3 \mathrm{~B}, 3 \mathrm{C}$ ). However, this difference was no longer present when colon sections were examined at eight and 12 weeks post-transfer (fig 3B, 3C).

Results presented above were obtained using mice in a C57BLKS/J background. However, comparable data were generated when mice in a C57BL/6 background were utilised (not shown). 

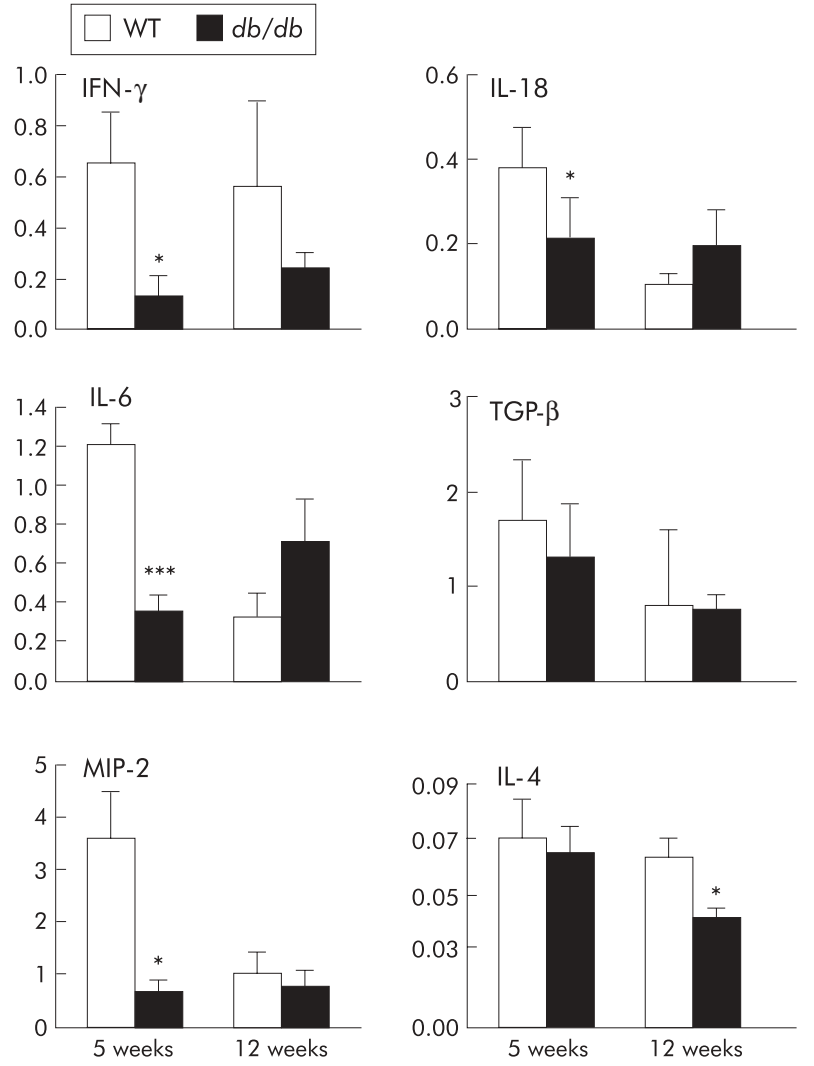

Figure 5 Altered cytokine production in colon cultures of mice receiving leptin receptor deficient $(d b / d b)$ RB high cells. Scid mice were injected with wild-type (WT) or $d b / d b R B^{\text {high }}$ cells. At weeks 5 and 12, a group of five mice per experimental group was sacrificed for evaluation of cytokine production by colon cultures. Data are mean (SEM). " $\mathrm{p}<0.05$, ${ }^{* * *} \mathrm{p}<0.001$ versus WT. IFN- $\gamma$, interferon $\gamma$; IL, interleukin; TGF- $\beta$, transforming growth factor $\beta$; MIP-2, macrophage inflammatory protein 2.

Serum corticosterone and glucose levels were evaluated in scid mice at the time of cell injection and found to be in the normal range (not shown).

\section{High levels of glucocorticoids (GC) do not alter disease progression}

High levels of GC are present in $d b / d b$ mice. ${ }^{19}$ We therefore evaluated whether delayed disease progression in scid mice receiving $d b / d b$ cells could be attributed to high levels of GC in donor mice. To this aim, a group of WT mice received corticosterone (CS) in drinking water for one month prior to isolation of $\mathrm{RB}^{\text {high }}$ cells from their spleen (WT-CS mice). Serum CS levels in WT-CS mice and $d b / d b$ mice were comparable and significantly higher than in WT mice (data not shown). Disease scores did not differ between scid mice receiving WT or WT-CS cells (data not shown), suggesting that the effect seen by injecting $d b / d b$ cells was not likely attributable to exposure to high GC levels.

\section{Characterisation of IEL, LPL, and MLN}

$\mathrm{CD}^{+}$cells injected into scid mice home to the gut and differentiate into $\mathrm{CD} 8^{+}$cells. ${ }^{20}$ To evaluate whether defective homing or differentiation could be responsible for the reduced ability of $d b / d b$ cells to induce disease, we compared the IEL and LPL populations of mice receiving WT or $d b / d b$ cells. However, at five weeks post-injection-the time point at which significantly reduced colonic inflammation was observed in mice treated with $d b / d b \mathrm{RB}^{\text {high }}$ cells-we did not find significant differences in terms of differentiation into $\mathrm{CD}^{+}$cells or expression of homing receptors between mice injected with WT and $d b / d b$ cells (data not shown). Furthermore, cell activation was evaluated by comparing surface expression of CD25 and CD69 on $\mathrm{CD}^{+}$MLN in scid mice injected with either WT or $d b / d b$ cells and no significant differences between the two groups were observed (data not shown).

Interestingly, at five weeks post-treatment, mice injected with $d b / d b$ cells had a rate of apoptosis in the LPL population similar to that of untreated Balb/c mice whereas apoptosis was markedly reduced in LPL of mice injected with WT cells (fig 4). However, the difference in LPL apoptosis between recipients of WT and $d b / d b$ cells was no longer evident at 12 weeks post-injection. At this time point, apoptosis of WT LPL was no longer reduced compared with LPL obtained from control mice or mice receiving $d b / d b$ cells (fig 4 ).

\section{Reduced early cytokine production in mice receiving $d b / d b R^{\text {high }}$ cells}

Cytokine production was measured in colon cultures and in LPL cultures of mice receiving WT or $d b / d b$ cells. Production of the cytokines and chemokines IFN- $\gamma$, IL-6, IL-18, and MIP-2 was significantly reduced in cultures obtained from the colon of recipients of $d b / d b$ cells compared with recipients of WT cells at five weeks post-injection (fig 5). However, when these cytokines were measured 12 weeks post-injection, differences between recipients of WT or $d b / d b$ cells were no longer present. The opposite results were obtained for IL-4, whose levels were similar early in disease but significantly lower in recipients of $d b / d b$ cells at 12 weeks post-injection. No significant differences between recipients of WT and $d b / d b$ cells were observed in terms of TGF- $\beta$ production. TNF- $\alpha$ and IL-10 were below detection limit in each of the colon cultures evaluated. Similar results were obtained with cultures of anti-CD3-stimulated LPL (fig 6).

\section{Increased expression of PPAR $\gamma$ in the colon of mice receiving $d b / d b R^{\text {high }}$ cells}

The nuclear receptor PPAR $\gamma$ has anti-inflammatory activities. ${ }^{21}$ We compared expression of PPAR $\gamma$ in the colon of mice that were transferred with WT or $d b / d b \mathrm{RB}^{\text {high }}$ cells five or 12 weeks earlier. As shown in fig 7, expression of PPAR $\gamma$ was higher in the colon of mice that had received $d b / d b$ compared with WT RB ${ }^{\text {high }}$ cells, irrespective of the time point analysed.

\section{Reduced cytokine production in freshly sorted $d b / d b$ RB ${ }^{\text {high }}$ cells}

We evaluated production of IFN- $\gamma$ and IL-10 in freshly sorted WT and $d b / d b \mathrm{RB}^{\text {high }}$ and $\mathrm{RB}^{\text {low }}$ cells. As expected, when stimulated with anti-CD3, alone or in combination with anti-CD28, WT RB high cells produced high levels of IFN- $\gamma$ (fig 8A, B). Interestingly, $d b / d b \mathrm{RB}^{\text {high }}$ cells stimulated with anti-CD3 alone produced low levels of IFN- $\gamma$ which were not different from those produced by $\mathrm{RB}^{\text {low }}$ cells (fig 8A). Costimulation with anti-CD3 and anti-CD28 overcame the reduced ability of $d b / d b \mathrm{RB}^{\text {high }}$ to produce IFN- $\gamma$ (fig 8B). In contrast, as expected, IL-10 was mostly produced by $\mathrm{RB}^{\text {low }}$ cells and no significant differences between WT and $d b / d b$ cells for production of this cytokine could be observed (fig 8C, D).

The transcription factor T-bet regulates production of IFN $-\gamma .{ }^{22}$ We investigated whether the reduced ability of $d b / d b \mathrm{RB}^{\text {high }}$ to produce IFN- $\gamma$ could be secondary to low levels of T-bet and therefore due to failure to differentiate 

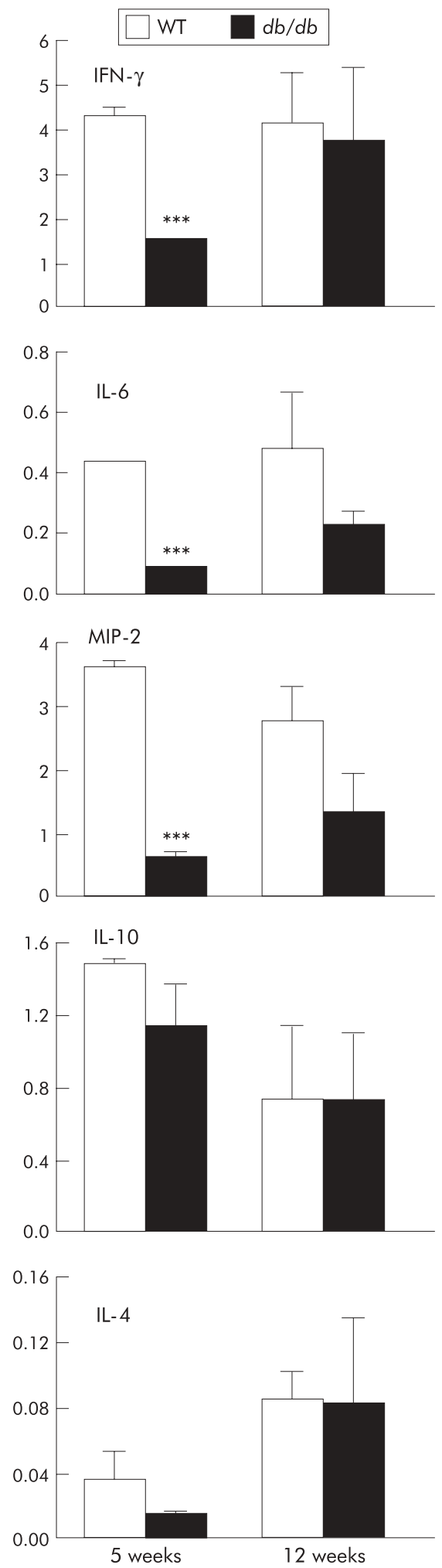

Figure 6 Altered cytokine production in lamina propria lymphocytes (LPL) of mice receiving leptin receptor deficient $(d b / d b)$ RB high cells. Scid mice were injected with wild-type (WT) or $d b / d b$ RB high cells. At weeks 5 and 12, a group of five mice per experimental group was sacrificed for evaluation of cytokine production by LPL stimulated with anti-CD3€. Data are mean (SEM). ${ }^{* *} \mathrm{p}<0.001$ versus WT. IFN $-\gamma$, interferon $\gamma$; IL, interleukin; MIP-2, macrophage inflammatory protein 2.

into Thl cells. However, similar amounts of T-bet were present in cell lysates of WT and $d b / d b \mathrm{RB}^{\text {high }}$ cells (fig $8 \mathrm{E}$ ).

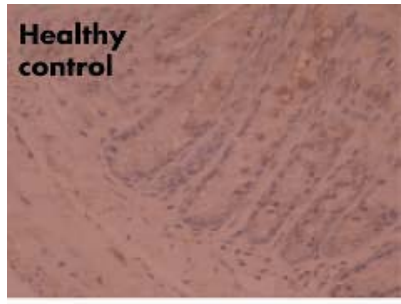

Figure 7 High expression of peroxisome proliferator activated receptor $\gamma($ PPAR $\gamma$ ) in the colon of mice receiving leptin receptor deficient $(\mathrm{db} / \mathrm{db}) \mathrm{RB}^{\mathrm{high}}$ cells. PPAR $\gamma$ expression was evaluated in the colon of scid mice that had received wild-type (WT) or $d b / d b$ $\mathrm{RB}^{\text {high }}$ cells five or 12 weeks earlier and in control mice.
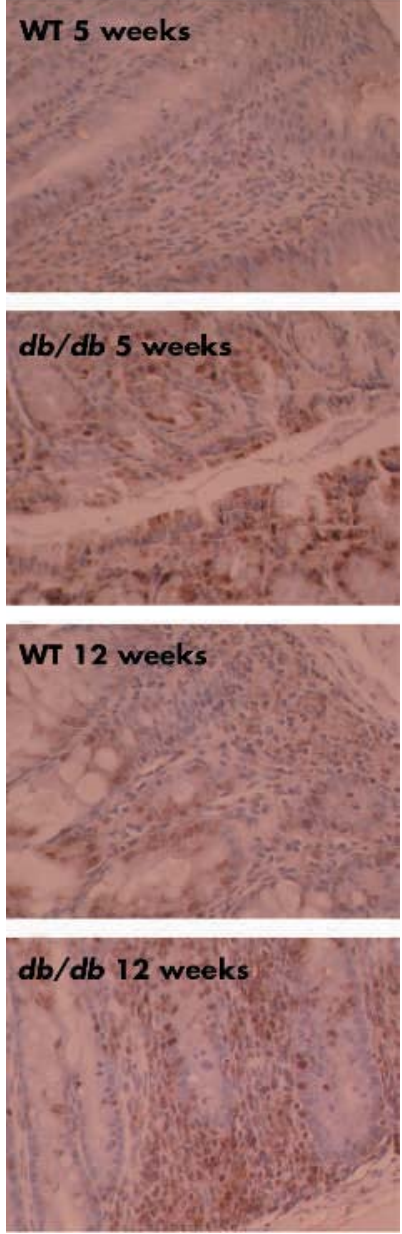

\section{DISCUSSION}

The results of the present studies indicate that a selective deficiency of LEPR-B on T lymphocytes leads to delayed development of intestinal inflammation. These results are in agreement with our previous observations indicating protection from colitis in $o b / o b$ mice. ${ }^{7}$ However, those previous data left open the question of whether a central or peripheral mechanism was involved in the observed effect.

The possible participation of a local leptin network in regulating intestinal inflammation is underscored by the presence of leptin receptors on both $\mathrm{RB}^{\text {high }}$ and $\mathrm{RB}^{\text {low }}$ cells and by expression of high leptin levels in LPL and MLN obtained from mice with intestinal inflammation. Furthermore, leptin modulated cytokine production in $\mathrm{RB}^{\text {high }}$ cells. On the other hand, the observation that intestinal inflammation was associated with reduced systemic leptin levels suggests that it is local rather systemic leptin that participates in the modulation of inflammatory responses.

Administration of $d b / d b \mathrm{RB}^{\text {high }}$ cells to scid mice induced significantly delayed disease compared with injection of WT cells. Recipients of $d b / d b$ cells were not completely protected from colitis but did eventually develop disease. This indicates 

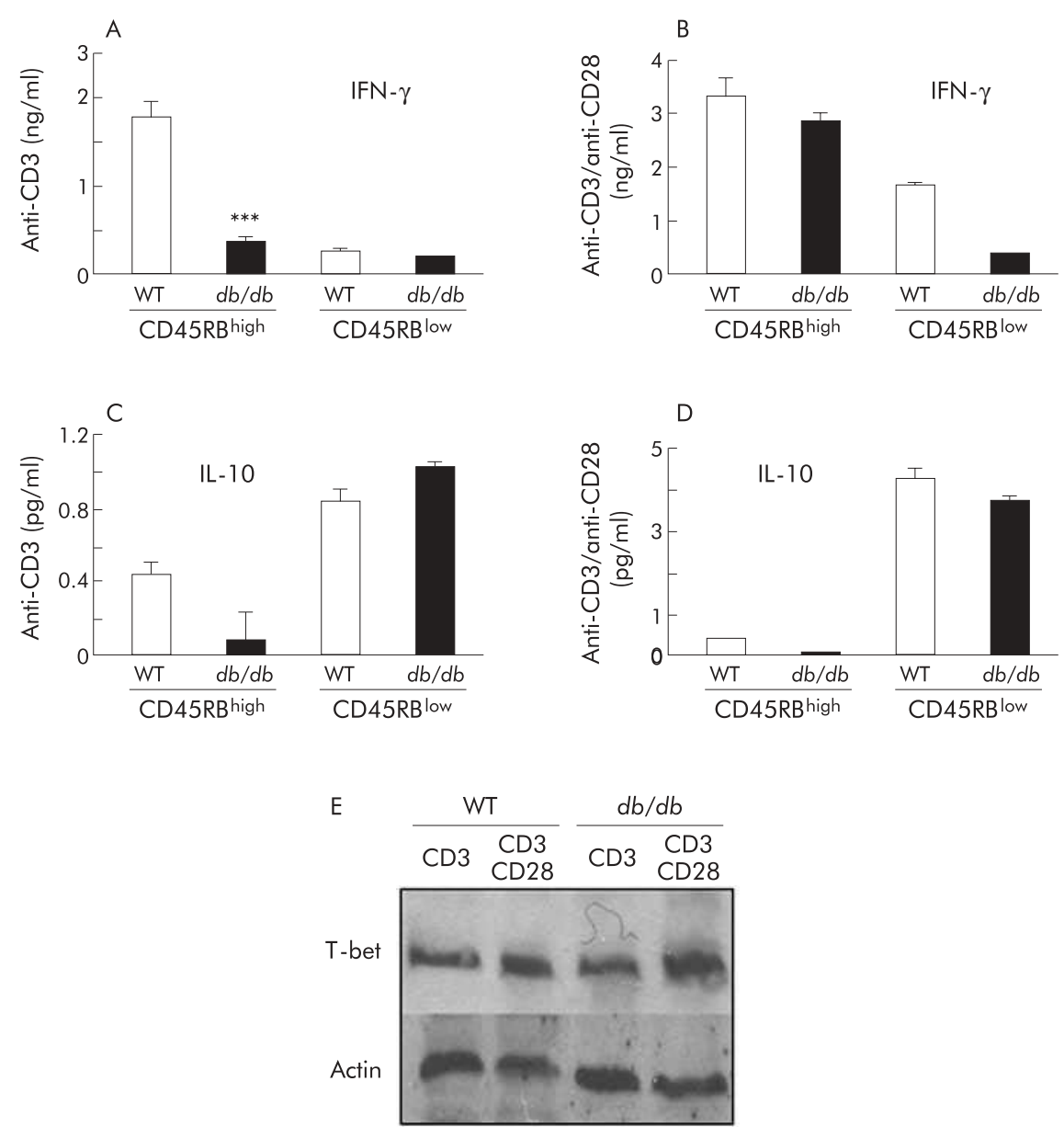

Figure 8 Cytokine production and T-bet expression in freshly sorted wild-type (WT) and leptin receptor deficient $(d b / d b) R B^{\text {high }}$ and RB ${ }^{\text {low }}$ cells. RB ${ }^{\text {high }}$ and $R B^{\text {low }}$ cells were isolated from the spleen of $W T$ and $d b / d b$ mice. Cells were stimulated with plate bound anti-CD3 $\epsilon$, in the absence $(A, C)$ or presence (B, D) of soluble anti-CD28. Interferon $\gamma$ (IFN- $\gamma$ ) (A, B) and interleukin 10 (IL-10) (C, D) levels were measured in culture supernatants. Data are mean (SEM) of four wells. ${ }^{* * *} p<0.001$ versus WT RB high cells. (E) Expression of T-bet was evaluated by western blot in unstimulated WT and $d b / d b$ $R B^{\text {high }}$ cells. Equal loading was evaluated using an antiactin antibody.

that the absence of LEPR-B does not completely alter the biological activity of $\mathrm{RB}^{\text {high }}$ cells. The current understanding of the disease inducing ability of $\mathrm{RB}^{\text {high }}$ cells proposes that, in the absence of regulatory $\mathrm{T}$ cells and suppressive cytokines in $\mathrm{T}$ cell deficient recipients, the aggressive Thl skewed donor $\mathrm{RB}^{\text {high }}$ cells undergo uncontrolled proliferation and activation, leading to colitis development. ${ }^{23}$ The observation that $d b / d b \mathrm{RB}^{\text {high }}$ cells do eventually induce colitis indicates that LEPR-B is not necessary for generation of disease inducing $\mathrm{T}$ cells, although it modulates their aggressivity. In addition, absence of LEPR-B on donor cells does not influence their ability to home to the gut and differentiate into $\mathrm{CD} 8^{+}$cells. Two possible interpretations exist for the present results: (i) a direct effect of leptin on LEPR-B expressed on transferred $\mathrm{RB}^{\text {high }}$ cells is necessary for the cells to fully express their aggressive phenotype; and (ii) the phenotypic behaviour of $\mathrm{RB}^{\text {high }}$ cells that have developed in a LEPR-B deficient environment is altered due to the effects of intermediate mediators present at different levels in $d b / d b$ versus WT mice. When cells are transferred into a LEPR-B competent organism, they have the ability to develop into fully aggressive cells, although prolonged exposure to the "normal" environment is necessary. The experiments using WTCS mice excluded the likelihood that the intermediate mediators could be GC. These results are in agreement with recent data by Mykoniatis et al showing that adrenalectomy does not reverse the resistance of $o b / o b$ mice to $C$ difficile toxin
A induced enteritis. ${ }^{8}$ However, other possible candidates exist. For example, we have demonstrated that expression of PPAR $\gamma$, a molecule whose levels are altered in $o b / o b$ and $d b / d b$ mice and that has been implicated in the regulation of inflammatory responses, ${ }^{21}{ }^{24}$ is higher in recipients of $d b / d b$ compared with WT cells, indicating that indirect mechanisms might contribute to the observed effects.

Lamina propria lymphocytes from normal subjects exhibit high rates of apoptosis while LPL from Crohn's disease patients are resistant to apoptotic stimuli. ${ }^{25}$ Previous results indicated that leptin acts as a protective factor in $\mathrm{T}$ lymphocyte apoptosis. ${ }^{1026}$ In particular, in previous studies we observed high rates of apoptosis in LPL of ob/ob mice which correlated with resistance in models of intestinal inflammation. ${ }^{7}$ In the present report, we showed that, compared with non-diseased animals, apoptosis was reduced early in disease in the LPL of scid mice that received WT $\mathrm{RB}^{\text {high }}$ cells but not in recipients of $d b / d b$ cells. However, at later time points, the rate of LPL apoptosis in recipients of WT RB ${ }^{\text {high }}$ cells increased to levels similar to those observed in control mice and in recipients of $d b / d b$ mice. This phenomenon could possibly be interpreted as an attempt to control inflammation by increasing rates of apoptosis late in disease.

Production of proinflammatory cytokines such as IFN- $\gamma$, IL-6, IL-18, and MIP-2 was reduced early in disease in recipients of $d b / d b \mathrm{RB}^{\text {high }}$ cells compared with mice injected 
with WT cells. However, these differences were not evident when levels of anti-inflammatory cytokines such as IL-10, IL-4, and TGF- $\beta$ were evaluated. This indicates that reduced early inflammation in recipient of $d b / d b \mathrm{RB}^{\text {high }}$ cells cannot be attributable to complete failure to produce cytokines but rather to a selective reduction of proinflammatory mediators. Furthermore, early protection from disease is not due to production of high levels of anti-inflammatory mediators.

Thl cytokines and transcription factors controlling Thl development are critical mediators in the model of colitis induced by transfer of $\mathrm{RB}^{\text {high }}$ cells. ${ }^{27}$ Although the mechanism is currently unknown, leptin controls production of Thl cytokines, mainly IFN $-\gamma \cdot{ }^{10}$ In the present study, we observed that freshly isolated $d b / d b \mathrm{RB}^{\text {high }}$ cells produced significantly lower amounts of IFN- $\gamma$ compared with WT cells when stimulated with anti-CD3, providing a potential mechanism explaining the lower aggressivity of $d b / d b \mathrm{RB}^{\text {high }}$ cells However, costimulation with anti-CD3 and anti-CD28 led to comparable production of IFN $-\gamma$ by WT and $d b / d b \mathrm{RB}^{\text {high }}$ cells, suggesting that defects in the costimulatory pathways might be involved.

A role for the Thl inducing transcription factor T-bet in different models of colitis has been described. ${ }^{27}$ T-bet deficient cells produce low levels of IFN- $\gamma$ and are unable to induce colitis in immunodeficient recipients, a pattern similar to the one we observed with $d b / d b$ cells. However, we found that $d b / d b \mathrm{RB}^{\text {high }}$ cells express $\mathrm{T}$-bet to the same extent as WT cells, thus excluding this putative mechanism.

In conclusion, our present work indicates that, in a model of chronic Thl mediated intestinal inflammation, the signal transducing isoform of the leptin receptor is an important regulator of $\mathrm{T}$ cell activity.

\section{ACKNOWLEDGEMENTS}

This work was supported by grants from the Broad Medical Research Program of the Eli and Edythe L Broad Foundation, the Crohn's and Colitis Foundation of America, National Institutes of Health DK061483 (to GF), by the Emmy-Noether program (DFG SI 749/31) of the Deutsche Forschungsgemeinschaft and DFG SI 749/2-1 (to BS), and by NCRR SERCA KO-1 RR16092 (to JJ-C).

\section{Authors' affiliations}

B Siegmund, A Batra, I Fedke, M Zeitz, Charite Universitaetsmedizin Berlin, Campus Benjamin Franklin, Medizinische Klinik I,

Hindenburgdamm 30, 12200 Berlin, Germany

J A Sennello, G Fantuzzi, Department of Medicine, University of Colorado Health Sciences Center, Denver, CO, USA

J Jones-Carson, Department of Microbiology, University of Colorado Health Sciences Center, Denver, CO, USA

F Gamboni-Robertson, Department of Surgery, University of Colorado Health Sciences Center, Denver, CO, USA

H A Lehr, Institute of Pathology, University of Mainz, Mainz, 55131, Germany

\section{REFERENCES}

1 Friedman JM, Halaas JL. Leptin and the regulation of body weight in mammals. Nature 1998;395:763-70.

2 Fantuzzi G, Faggioni R. Leptin in the regulation of immunity, inflammation and hematopoiesis. J Leukoc Biol 2000;68:437-46.

3 Sanna V, Di Giacomo A, La Cava A, et al. Leptin surge precedes onset of autoimmune encephalomyelitis and correlates with development of pathogenic T cell responses. J Clin Invest 2003;111:241-50.

4 Faggioni R, Jones-Carson J, Reed DA, et al. Leptin-deficient (ob/ob) mice are protected from T cell-mediated hepatotoxicity: role of tumor necrosis factor- $\alpha$ and IL-18. Proc Natl Acad Sci U S A 2000;97:2367-72.

5 Busso N, So A, Chobaz-Peclat V, et al. Leptin signaling deficiency impairs humoral and cellular immune responses and attenuates experimental arthritis. J Immunol 2002; 168:875-82.

6 Matarese G, Di Giacomo A, Sanna V, et al. Requirement for leptin in the induction of autoimmune encephalomyelitis. J Immunol 2001;166:5909-16.

7 Siegmund B, Lehr HA, Fantuzzi G. Leptin: a pivotal mediator of intestinal inflammation. Gastroenterology 2002;122:201 1-25.

8 Mykoniatis A, Anton PM, Wlk M, et al. Leptin mediates Clostridium difficile toxinA-induced enteritis in mice. Gastroenterology 2003; 124:683-91.

9 Cohen $\mathrm{P}$, Zhao $\mathrm{C}$, Cai X, et al. Selective deletion of leptin receptor in neurons leads to obesity. J Clin Invest 2001;108:1113-21.

10 Lord GM, Matarese G, Howard JK, et al. Leptin modulates the T-cell immune response and reverses starvation-induced immunosuppression. Nature 1998:394:897-901.

11 Martin-Romero C, Santos-Alvarez J, Goberna R, et al. Human leptin enhances activation and proliferation of human circulating T lymphocytes. Cell Immunol 2000;199:15-24

12 Zarkesh-Esfahani H, Pockley G, Metcalfe RA, et al. High-dose leptin activates human leukocytes via receptor expression on monocytes. J Immunol 2001;167:4593-9.

13 Powrie F, Leach MW, Mauze S, et al. Inhibition of Th1 responses prevents inflammatory bowel disease in scid mice reconstituted with CD45RB ${ }^{\text {hi }} \mathrm{CD} 4^{+}$ cells. Immunity 1994; 1:553-62.

14 Groux $\mathrm{H}, \mathrm{O}^{\prime}$ Garra $\mathrm{A}$, Bigler $\mathrm{M}$, et al. $\mathrm{A} C D 4^{+} \mathrm{T}$-cell subset inhibits antigenspecific T-cell responses and prevents colitis. Nature 1997;389:737-42.

15 Siegmund B, Fantuzzi G, Rieder F, et al. Neutralization of IL-18 reduces severity in murine colitis and intestinal IFN- $\gamma$ and TNF- $\alpha$ production. Am J Physiol 2001;281:R1264-73.

16 Siegmund B, Lehr HA, Fantuzzi G, et al. IL-1 $\beta$-converting enzyme (caspase-1) in intestinal inflammation. Proc Nat Acad Sci U S A 2001;98:13249-54.

17 Fantuzzi G, Reed DA, Dinarello CA. Interleukin (IL)-12-induced interferongamma is dependent on caspase-1 processing of the IL-18 precursor. J Clin Invest 1999; 104:761-7.

18 Melnikov VY, Ecder T, Fantuzzi G, et al. Protection against ischemic acute renal failure in caspase-1 deficient mice: role of interleukin-18. J Clin Invest 2001; 107:1145-52.

19 Saito M, Bray GA. Diurnal rhythm for corticosterone in obese (ob/ob) diabetes $(\mathrm{db} / \mathrm{db})$ and gold-thioglucose-induced obesity in mice. Endocrinology 1983;113:2181-5.

20 Aranda R, Sydora BC, McAllister PL, et al. Analysis of intestinal lymphocytes in mouse colitis mediated by transfer of CD4 ${ }^{+}, \mathrm{CD} 45 \mathrm{RB}$ high $\mathrm{T}$ cells to SCID recipients. J Immunol 1997; 158:3464-73.

21 Wada K, Nakajima A, Blumberg RS. PPAR $\gamma$ and inflammatory bowel disease: a new therapeutic target for ulcerative colitis and Crohn's disease. Trends Mol Med 2001;7:329-31.

22 Szabo SJ, Tim ST, Costa GL, et al. A novel transcription factor, T-bet, directs Th1 lineage commitment. Cell 2000;100:655-69.

23 Groux H, Powrie F. Regulatory T cells and inflammatory bowel disease. Immunol Today 1999;20:442-5.

24 Vidal-Pluig A, Jimenez-Linan M, Lowell BB, et al. Regulation of PPAR $\gamma$ gene expression by nutrition and obesity in rodents. $J$ Clin Invest 1996;97:2553-61.

25 Neurath M, Finotto S, Fuss IJ, et al. Regulation of T-cell apoptosis in inflammatory bowel disease: to die or not to die, that is the mucosal question. Trends Immunol 2001;22:21-6

26 Fujita Y, Murakami M, Ogawa Y, et al. Leptin inhibits stress-induced apoptosis of T lymphocytes. Clin Exp Immunol 2002;128:21-6.

27 Neurath MF, Weigmann B, Finotto S, et al. The transcription factor T-bet regulates mucosal T cell activation in experimental colitis and Crohn's disease. $J$ Exp Med 2002;195: 1129-43. 